American Journal of Environmental Sciences 5 (5): 633-638, 2009

ISSN 1553-345X

(C) 2009 Science Publications

\title{
Landscape Change and Sandy Desertification Monitoring and Assessment
}

\author{
${ }^{1,2}$ Eltahir Mohd Elhadi, ${ }^{2}$ Nagi Zomrawi and ${ }^{1} \mathrm{Hu}$ Guangdao \\ ${ }^{1}$ Department of Geomathematic and Remote Sensing, Faculty of Earth Resources, \\ China University of Geosciences, Wuhan, 430074, China \\ ${ }^{2}$ Department of Surveying Engineering, Faculty of Engineering, \\ Sudan University of Science and Technology, Khartoum, Sudan
}

\begin{abstract}
Problem statement: The objective of this study is to develop techniques for assessing and analyzing sand desertification in the northern part of Shaanxi Province, China. Approach: In order to reveal the process of land degradation, especially the latest situation of sandy desertification, a method integrating remote sensing, Geographic Information System (GIS) and field survey was employed to build a sandy desertification dataset for analysis. Remote Sensing images included the Landsat Thematic Mapper (TM) images in 1987 and Landsat Enhanced Thematic Mapper Plus (ETM+) images in 1999). Eight land-cover classes, including active sand dunes, fixed sand dunes, semi-fixed sand dunes, grass land, farm land, wet land, built up area and unused land and Normalized Difference Vegetation Index (NDVI), were identified. Results: The results showed that the active sand dunes and semi-fixed sand dunes have increased with a change rate of 128.70 and $55.65 \mathrm{~km}^{2}$ year ${ }^{-1}$, respectively, in the meantime the fixed sand dunes has decreased with a decreasing rate of $182.14 \mathrm{~km}^{2}$ year ${ }^{-1}$. During the $1987 \mathrm{~s}$, the area of sandy desertified land reached $12,006.11 \mathrm{~km}^{2}(57.17 \%$ of the total sandy area), of which severely desertified, medium desertified and slightly desertified land areas were $4,442.23,4,253.45$ and $3,310.43 \mathrm{~km}^{2}$, respectively. By the year 1999 , the area of desertified land was increased to $13,782.30 \mathrm{~km}^{2}$ ( $65.63 \%$ of the total sandy area), of which severely desertified, medium desertified and slightly desertified land areas were 5,169.89, 4,918.15 and 3,694.26 km², respectively increasing by $1,776.19 \mathrm{~km}^{2}$. Conclusion: Spatial change detection based on active sand dunes showed that the expansion area was much larger than the reversion in the past two decades and that several active sand belts has been formed, suggesting that sandy desertification of northern part of Shaanxi Province, China, will be a long-term task.
\end{abstract}

Key words: Assessment, sandy desertification, NDVI, active sand dunes, GIS, China

\section{NTRODUCTION}

The term "desertification" should be used side by side with the term "land degradation". Hence "desertification" in the context of assessment is land degradation in arid; semi-arid and sub-humid areas resulting from adverse human impact. According to the United Nations Conference on Environment and Development ${ }^{[13]}$, defines desertification as "land degradation in arid, semi-arid and dry sub-humid areas resulting from various factors including climatic variations and human activities.

Sandy desertification is one of the main form of land degradation in China, especially in northern China ${ }^{[9]}$, which has kept expanding since the 1950's and has exerted severe impacts on regional socioeconomic development and environmental security ${ }^{[11]}$.
Harsh physiographic conditions (sparse vegetation coverage, sandy soil and water deficiency), irrational land-use practice and population augmentation are regarded as the forces of triggering sandy desertification $^{[3]}$ Therefore, the sandy desertification assessment and monitoring are always concerned by researchers, the public and the policy-makers.

Desert and sandy decertified land occupy about 1.67 million $\mathrm{km}^{2}$, or $17 \%$ of the total land area of China ${ }^{[10]}$. Decertified sandy land increased by 25,200 $\mathrm{km}$ for the period from 1975-1987 about $40.5 \%$ of which was distributed in the semi-arid agro-pastoral regions of northern China ${ }^{[16]}$.

The objective of this study is to develop techniques for assessing and analyzing sand desertification in the northern part of Shaanxi Province, China, in the past decades. A method of integrating Remote Sensing (RS),

Corresponding Author: Eltahir Mohd Elhadi, Department of Geomathematic and Remote Sensing, Faculty of Earth Resources, China University of Geosciences, Wuhan, 430074, China Tel: +862736962740 Fax: +862787515956 
Geographic Information System (GIS) and field survey was employed to generate a sandy desertification dataset of this region. Then change detection and land degradation process were performed based on the dataset. This study intends to provide useful information for sandy desertification controlling and environmental management of the northern part of Shaanxi Province, China.

\section{MATERIALS AND METHODS}

Study area: The study area, located in the northern part of Shaanxi province, lies within longitude $108^{\circ} 33$ $111^{\prime} 24^{\prime \prime} \mathrm{E}$ and from $36^{\circ} 97-39^{\prime} 58^{\prime \prime} \mathrm{N}$ with total area of $29416.6 \mathrm{~km}^{2}$, accounting for $18.6 \%$ of the total Shaanxi province (Fig. 1). In order to study the development of sandy desertification, the counties of Dingbian, Jingbian, Hengshan, Yulin and Shenmu have been selected as study area. Counties are situated in the northern part of Shaanxi province. Geographically, the study area is located in the transitional zone, in south and east of Mu Su Desert (Inner Mongolia) and the Loess Plateau of northern Shaanxi province in China. This area has atypical continental semi-arid climate.

Data sources: Satellite remote sensing, in conjunction with Geographic Information System (GIS), has been widely applied and been recognized as a powerful and effective tool in detecting landscape change ${ }^{[1,5,6]}$. Four kinds of data were used in this study, i.e., socioeconomic data, topographic data, remote sensing data and ancillary data. Socioeconomic data were the annual statistical data released by the National Bureau of Statistics. The data published in 1986 and 2001 were acquired. All data were amalgamated to the county level. Tow topographic maps had a scale of 1: 100,000 and 1: 50,000, respectively. The remote sensing data are landsat TM images record in 1987 and 1999. Two types of ancillary data were used, a vegetation map at a scale of 1: 500, 000 and a current land use map supplied Yulin Land and Resources Bureau ${ }^{[14]}$.

Data and pre-processing: Remote Sensing images used in this study include the Landsat-5 Thematic Mapper (TM) image and Landsat-7 Enhanced Thematic Mapper Plus (ETM+) image, which were acquired in 24 October 1987 and 15 October 1999, respectively, the pre-processing of this dataset included geometric corrections. All images were geometrically corrected not only to eliminate geometric distortions present in the images but also to register the satellite images to

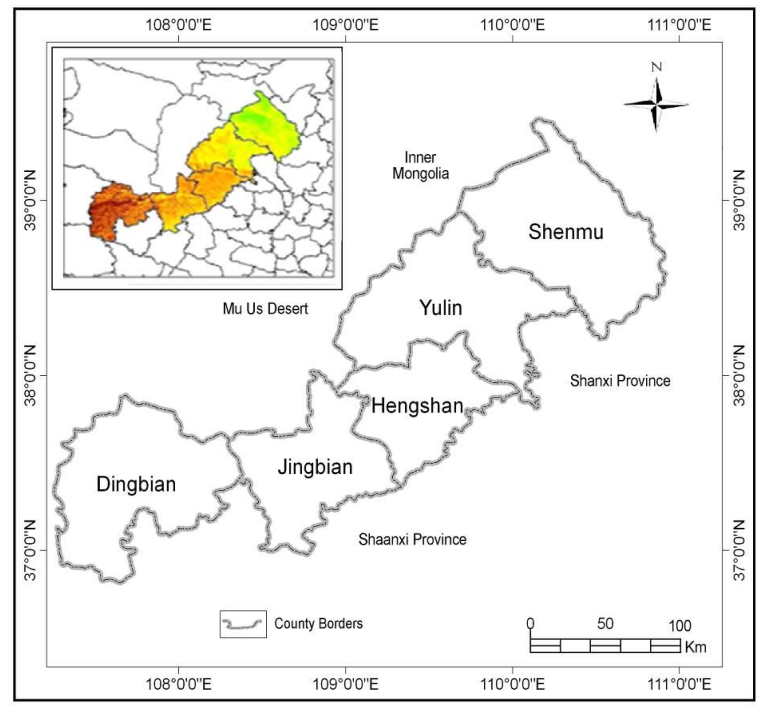

Fig. 1: General location map of study area

ground data. The nearest-neighbor resampling method was used in datum WGS 84 and projection UTM (49N) all images resampled to a $30 \mathrm{~m}$ pixel grid. In order to remove or normalize the reflectance variation between images acquired at different times, relative radiometric correction was performed to yield normalize radiometric data on a common scale ${ }^{[7]}$. Here, the histogram normalization, a simpler and more effective technique, was used to carry out the relative radiometric correction.

Determination of NDVI threshold: The Vegetation index can reflect a series of physics quantity of the plants, such as index of leaf's area, plant overlays degree, amount of living creature and plant category ${ }^{[8]}$. The index of vegetation contain many different expression methods, among them NDVI is applied in the fixed amount research of plant overlays. Therefore TM data were used to produce Normalize Difference Vegetation Index ${ }^{[4]}$, which is defined as:

$$
\text { NDVI = (TM4-TM3)/(TM4+TM3) }
$$

where, TM4 and TM3 are channels in the Near Infrared (NIR) and the Red (R) wavelength of landsat TM data, respectively, was applied for monitoring vegetation changes in the study area within the year 1987 and 1999.

Determining the threshold of NDVI is the first step in extraction of sand desertification. Then we can use the threshold to separate vegetation information and non-vegetation information from land cover. Through comparative analysis of the NDVI images and the 
research area, select NDVI $=0.05$ as the threshold, which can separate vegetation information and nonvegetation information from the research land cover. That is: If NDVI $>0.05$, the area was considered as vegetation; instead, considered as no vegetation information.

The vegetation cover is a primary indicator of land desertification. Before the data modeling, NDVI was density sliced. We defined that if NDVI was less than 0.078 , vegetation cover percentage was less than $15 \%$; if NDVI was between 0.079 and 0.102 , vegetation cover percentage was between 15-30\%; If NDVI was between 0.103 and 0.138 , vegetation cover was between $30-$ $50 \%$.

The NDVI and vegetation cover classification criteria were defined as follows: NDVI $<0.079$ and vegetation cover $<15 \%$ as active sandy land and it is severe desertified, NDVI $=0.079-0.102$ and vegetation cover $=15-30 \%$ as semi-fixed sandy land and it is medium desertified and NDVI $=0.103-0.138$ and vegetation cover $=30-50 \%$ as fixed sandy land and it is slightly desertified. This NDVI classification was calibrated by field work and was also supported by previous studies ${ }^{[2,15]}$.

The image pattern, tone and texture were considered to classify the land types of sandy desertification. The following four types were mapped:

- Land severely affected by sandy desertification. This is characterized by a grayish bright color and represent mobile sandy dunes with sickle-like shapes and high undulation which has $<15 \%$ vegetation cover. The active sand dunes are widespread, covering up to $50-70 \%$ of the total area of sandy land. The inter-dune areas are characterized by wind erosion and sand covering

- Land showing a medium amount of sandy desertification. This type of sandy land has a gray or grayish red color and exhibits semi-fixed sand dunes with a wave-like shape. The vegetation cover varies from $15-30 \%$. The shifting sand is widespread and there are visible patches of wind erosion in farmland and grassland

- Land slightly affected by desertification. Grayish green and grayish red in color, it refers to fixed dunes with little shifting sand and has a vegetation cover of $30-50 \%$

- Land unaffected by desertification. This has a uniforml saturated red color and has no patches of shifting sand and a vegetation cover of more than $50 \%$

\section{RESULTS}

Landscape change: Generally speaking, from the 1987 s to the 1999 s, there was a remarkable ecological



Fig. 2: Landscape of the study area in 1987

change occurred in the study area sandy land during the study period (12 years). The sandland landscape changed significantly and desertified land has expanded rapidly. From 1987-1999, the fixed sand dunes, which, covered $\left(9669.24 \mathrm{~km}^{2} ; 32.87 \%\right)$ of the total area in 1987, sharply shrank to $7483.58 \mathrm{~km}^{2}(25.44 \%)$ in 1999 with a decreasing rate of $182.14 \mathrm{~km}^{2}$ year ${ }^{-1}$. The semifixed sand dunes, however, increased from $4121.27 \mathrm{~km}^{2}$ $(14.01 \%)$ in 1987 to $4789.02 \mathrm{~km}^{2}(16.28 \%)$ in 1999 with a growth rate of $55.65 \mathrm{~km}^{2}$ year ${ }^{-1}$. The active sand dunes, following the same trend as the semi-fixed sand dunes, increased from $5674.46 \mathrm{~km}^{2}(19.29 \%)$ in 1987 to $7218.83 \mathrm{~km}^{2}(24.54 \%)$ in 1999 with a change rate of $128.70 \mathrm{~km}^{2}$ year $^{-1}$. The grasslands decreased from $4244.82 \mathrm{~km}^{2}(14.43 \%)$ in 1987 to $2541.60 \mathrm{~km}^{2}$ $(8.64 \%)$ in 1999 with a decreasing rate of $141.94 \mathrm{~km}^{2}$ year ${ }^{-1}$, while the farmlands, increased rapidly from $1723.81 \mathrm{~km}^{2} \quad(5.86 \%)$ in 1987 to $3403.50 \mathrm{~km}^{2}(11.57 \%)$ in 1999 with a growth rate of change $139.97 \mathrm{~km}^{2}$ year ${ }^{-1}$. The built up area increased from $1106.05 \mathrm{~km}^{2}$ (3.76) in 1987 to $1741.46 \mathrm{~km}^{2}$ (5.92) in 1999, while the unused land decreased from $2100.35 \mathrm{~km}^{2}$ (7.14) in 1987 to $1582.61 \mathrm{~km}^{2}$ (5.38) in 1999, whereas wetlands had kept with no changed mentioned during the study period (Table 1 and Fig. 24). Policies have played an important role in controlling sandy desertification, this mainly happened in the study area as we can see in the rapidly increasing of farmland from $2017.98 \mathrm{~km}^{2}(6.86 \%)$ in 1987 to $3697.67 \mathrm{~km}^{2}$ $(12.57 \%)$ in 1999 of the total area, on the other hand we can see the decreasing of grassland from $4244.82 \mathrm{~km}^{2}$ (14.43\%) in 1987 to $2541.60 \mathrm{~km}^{2}(8.64 \%)$ in 1999 of the total area of the study area. Although land desertification has been to some extent controlled in the study area, the issue is still serious. 
Am. J. Environ. Sci., 5 (5): 633-638, 2009

Table 1: Change rate of the 8 landscape patterns from 1987-1999

\begin{tabular}{|c|c|c|c|c|c|c|c|}
\hline \multirow[b]{2}{*}{ Land cover types } & \multicolumn{2}{|l|}{1987} & \multicolumn{2}{|l|}{1999} & \multicolumn{2}{|c|}{ 1987-1999 } & \multirow{2}{*}{$\begin{array}{l}\text { Change rate } \\
\mathrm{km}^{2} \text { year }^{-1}\end{array}$} \\
\hline & $\mathrm{km}^{2}$ & Percent & $\mathrm{km}^{2}$ & Percent & $\mathrm{km}^{2}$ & Percent & \\
\hline Fixed sand dunes & 9669.24 & 32.870 & 7483.58 & 25.44 & 2185.66 & 7.43 & -182.140 \\
\hline Semi- fixed sand dunes & 4121.27 & 14.010 & 4789.02 & 16.28 & -667.75 & -2.27 & +55.650 \\
\hline Active sand dunes & 5674.46 & 19.290 & 7218.83 & 24.54 & -1544.37 & -5.25 & +128.700 \\
\hline Grass lands & 4244.82 & 14.430 & 2541.60 & 8.64 & 1703.22 & 5.79 & -141.940 \\
\hline Farm lands & 1723.81 & 5.860 & 3403.50 & 11.57 & -1679.69 & -5.71 & +139.970 \\
\hline Wet lands & 776.60 & 2.640 & 655.100 & 2.23 & 121.50 & 0.41 & -10.125 \\
\hline Built up area & 1106.05 & 3.760 & 1741.460 & 5.92 & -635.41 & -2.16 & +52.950 \\
\hline Unused land & 2100.35 & 7.140 & 1582.610 & 5.38 & 517.74 & 1.76 & +43.150 \\
\hline Total & 29416.60 & 100.000 & 29416.600 & 100.00 & & & 29416.60 \\
\hline
\end{tabular}

Table 2: Desertified land area during the study period

\begin{tabular}{|c|c|c|c|c|c|c|c|c|}
\hline \multirow[b]{2}{*}{ Year } & \multicolumn{2}{|c|}{ Severe desertification } & \multicolumn{2}{|c|}{ Medium desertification } & \multicolumn{2}{|c|}{ Slight desertification } & \multicolumn{2}{|c|}{ Unaffected land } \\
\hline & $\mathrm{km}^{2}$ & Percent & $\mathrm{km}^{2}$ & Percent & $\mathrm{km}^{2}$ & Percent & $\mathrm{km}^{2}$ & Percent \\
\hline 1987 & $4,442.23$ & 36.99 & $4,253.45$ & 35.43 & $3,310.43$ & 27.57 & $8,993.89$ & 42.83 \\
\hline 1999 & $5,169.89$ & 37.51 & $4,918.15$ & 35.68 & $3,694.26$ & 26.80 & $7,217.70$ & 34.37 \\
\hline
\end{tabular}



Fig. 3: Landscape of the study area in 1999

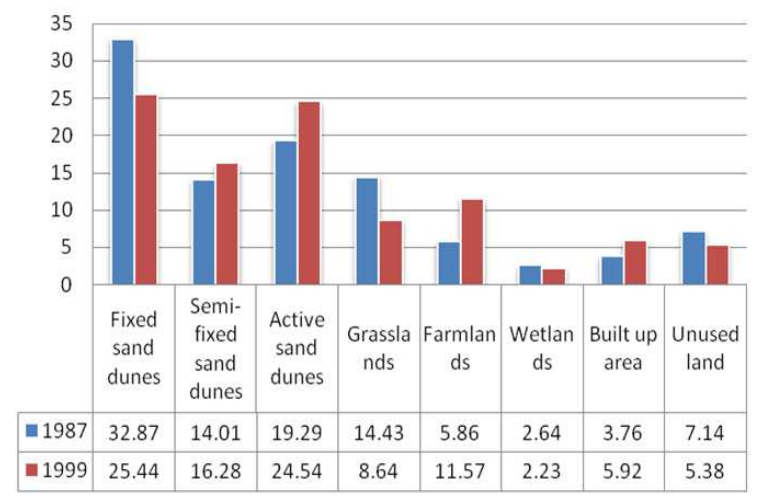

Fig. 4: Area percentage of the eight landscape patterns in 1987 and 1999

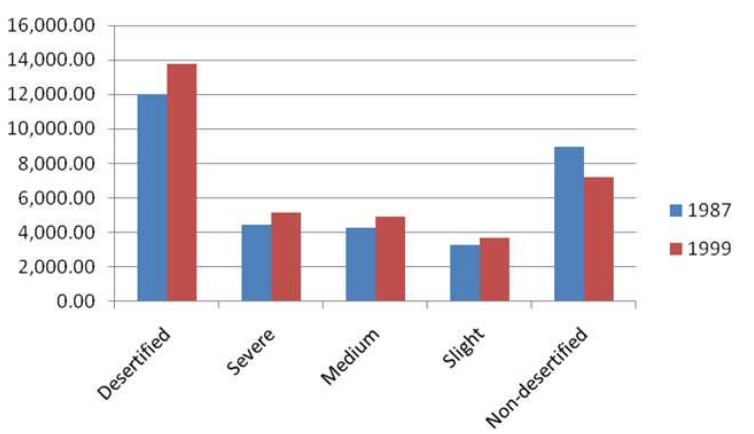

Fig. 5: Area of desertified land

Severity of sandy desertification: The sandy desertification land in the study area during the two different time intervals is indicated in Fig. 5. During the $1987 \mathrm{~s}$, the area of sandy desertified land reached $12,006.11 \mathrm{~km}^{2}(57.17 \%$ of the total sandy area), of which severely desertified, medium desertified and slightly desertified land areas were 4,442.23, $4,253.45$ and $3,310.43 \mathrm{~km}^{2}$, respectively. By the year 1999 , the area of desertified land was increased to $13,782.30 \mathrm{~km}^{2}(65.63 \%$ of the total sandy area), of which severely desertified, medium desertified and slightly desertified land areas were 5,169.89, 4,918.15 and $3,694.26 \mathrm{~km}^{2}$, respectively increasing by $1,776.19 \mathrm{~km}^{2}$. The statistics indicate that the unchanged region for the type of sandy desertification in 1987 reached $8,993.89 \mathrm{~km}^{2}$, accounting for $42.83 \%$ of the sandy area. While in 1999 it was reached $7,217.70 \mathrm{~km}^{2}$, accounting for $34.37 \%$ of the sandy area. It is indicated by the above data that the land desertification process was not steady and showed a trend of developing. The developed region of sandy desertification was directed mainly from the northwest towards the southeast, especially in the desert-adjacent areas. 
Spatial imbalance of sandy desertification: Table 2 shows the spatial imbalance of sandy desertification during the 12 years from 1987-1999. The regions with serious sandy desertification are in northwestern parts whereas those slightly influenced by desertification are in the southeastern parts belonging to loess hills. This imbalance of spatial distribution varied little during the 12 year study period and could be accounted for by the difference of physical factors and by the diversity of land-use practices. Compared to the southeast, the northwest, which is closer to the inner part of the MU US Desert, mainly under the influence of wind erosion and eolian accumulation, has an abundant sand source.

\section{DISCUSSION}

During the 1987s, the area of sandy desertified land reached $12,006.11 \mathrm{~km}^{2}(57.17 \%$ of the total sandy area), of which severely desertified, medium desertified and slightly desertified land areas were 4,442.23, $4,253.45$ and $3,310.43 \mathrm{~km}^{2}$, respectively. By the year 1999 , the area of desertified land was increased to $13,782.30 \mathrm{~km}^{2}(65.63 \%$ of the total sandy area), of which severely desertified, medium desertified and slightly desertified land areas were 5,169.89, 4,918.15and $3,694.26 \mathrm{~km}^{2}$, respectively increasing by $1,776.19 \mathrm{~km}^{2}$. The statistics indicate that the unchanged region for the type of sandy desertification in 1987 reached $8,993.89 \mathrm{~km}^{2}$, accounting for $42.83 \%$ of the sandy area. While in 1999 it was reached $7,217.70 \mathrm{~km}^{2}$, accounting for $34.37 \%$ of the sandy area.

\section{CONCLUSION}

The results also demonstrate that land cover changes during the past twelve years have been caused by land desertification on farmland and grassland in the area. Such changes may not only include the development of land desertification, but also explain the causes of land desertification in the study area due to over-exploitation and inappropriate land use, as well as by the invasion of wind-blown sand.

We can conclude from the results that the sandy desertification process of the northern part of Shaanxi Province, China, during the study period (twelve years) was a severe sandy desertification, characterized by the fixed sand dunes decreasing at a high speed and the semi-fixed and active sand dunes increasing remarkably. In most of the sand land, desertification has developed rabidly, while rehabilitation of vegetation has occurred only in marginal areas in the east and south.

\section{ACKNOWLEDGEMENT}

Many thanks to Professor $\mathrm{Hu}$ Guangdao at the Institute of Geomathematic and Remote Sensing, faculty of Earth Resources, China University of Geosciences, for providing the data.

\section{REFERENCES}

1. Allen S. Hope and Douglas A. Stow, 1993. An analysis of tree mortality in southern California using high spatial resolution remotely sensed spectral radiances: A climatic change scenario. Landscape Urban Plan., 24: 87-94. DOI: 10.1016/0169-2046(93)90087-T

2. Bo $\mathrm{Wu}$ and Long J. Ci, 2001. Landscape change and desertification development in the $\mathrm{Mu}$ Us Sandland, Northern China. J. Arid Environ., 50: 429-444. DOI: 10.1006/jare.2001.0847

3. Chen, Y.F. and H.P. Tang, 2005.Desertification in north China: Background, anthropogenic impacts and failures in combating it. Land Degradat. Dev., 16: 367-376. DOI: 10.1002/dr.667

4. Dall'Olmo, G. and A. Karnieli, 2002. Monitoring phenological cycles of desert ecosystem using NDVI and LST data derived from NOAA-AVHRR imagery. Int. J. Remote Sens., 23: 4055-4071. DOI: 10.1080/01431160110115988

5. Hui-Mei, H.A.O. and R.E.N. Zhi-Yuan, 2009. Land Use/Land Cover Change (LUCC) and ecoenvironment response to LUCC in farming-pastoral zone, China. Agric. Sci. China, 8: 91-97. DOI: 10.1016/S1671-2927 (09)60013-4

6. Liu, Y.S., J. Gao and Y.F. Yang, 2003. A holistic approach towards assessment of severity of land degradation along the Great Wall in northern Shaanxi Province, China. Environ. Monitor. Assess., 82: 187-202. ISSN: 0167-6369.

7. Paolini, L., F. Crings and J.A. Sobrino et al., 2006. Radiometric correction effects in Landsat multidate/multi-sensor change detection studies. Int. J. Remote Sens., 27: 685-704. DOI: 10.1080/01431160500183057

8. Qingjiu Tian and Xiangjun Min, 1998. The progress of the vegetation index research. Prog. Earth $\quad$ Sci., $\quad$ 13: 4:327-333. http://www.isprs.org/congresses/beijing2008/proce edings/7_pdf/5_WG-VII-5/47.pdf

9. Wang, G.X., J. Qian, G. Cheng and Y. Lai, 2001. Eco-environmental degradation and causal analysis in the source region of the Yellow River. Environ. Geol., 40: 884-890. DOI: 10.1007/s002540100248 
10. Wang Tao, Wu Wei and Chen Guangting, 2003. Study of spatial distribution of land desertification in North China in recent 10 years. Sci. China, 34: 73-82.

11. Wang, T., G.T. Chen and H.L. Zhao et al., 2006. Research progress on Aeolian desertification process and controlling in north of China. J. Desert Res., 26, 4: 507-516. ISSN: 1000-694X(2006)040507-10

12. Wang Tao, Zhu Zhenda and Wu Wei., 2002. Sandy desertification in the north China. Sci. China, 45: 23-34.

http://www.casnw.net/desertlabweb/production/pap ersci.htm

13. UNCED., 1992. Managing fragile ecosystems: Combating desertification and drought United Nations conference on environment and development. http://habitat.igc.org/un-proc/\#unced
14. Yulin Land and Resources Bureau, 2000. Current land use maps of Yulin. Unpublished.

15. Zhang, Y., Z. Chen, B. Zhu, X. Luo, Y. Guan, S. Guo and Y. Nie, 2007. Land desertification monitoring and assessment in Yulin of Northwest China using remote sensing and Geographic Information Systems (GIS). Environ. Monit. Assess., 147: 327-337. DOI: 10.1007/s10661-0070124-2

16. Zhu, Z. and T. Wang, 1993. Trends in desertification and its rehabilitation in China. Desertif. Control Bull., 22: 27-30. http://www.ciesin.columbia.edu/docs/002-224/002224.html 